\title{
Variability in Dust Observed over China Using A-Train CALIOP Instrument
}

\author{
Hui Xu, Fengjie Zheng, and Wenhao Zhang \\ Institute of Remote Sensing and Digital Earth, Chinese Academy of Sciences, Beijing 100101, China
}

Correspondence should be addressed to Hui Xu; xhradi@163.com

Received 1 April 2016; Accepted 25 May 2016

Academic Editor: Noemí Perez

Copyright (C) 2016 Hui Xu et al. This is an open access article distributed under the Creative Commons Attribution License, which permits unrestricted use, distribution, and reproduction in any medium, provided the original work is properly cited.

\begin{abstract}
Patterns of dust aerosol variation over China are analyzed using A-Train CALIOP and precipitation, soil moisture, and vegetation coverage datasets during the period of 2007 and 2014. Spatially, dust is mostly prominent over northwestern China, with the highest and most widespread dust activities being in Taklimakan Desert. Dust is generally distributed across the atmosphere up to $5 \mathrm{~km}$ altitude, with a peak of DAFOD around $3 \mathrm{~km}$. The dust layer has a significant geographical and seasonal drifting, with higher altitude in spring and summer and dust source regions (between $3 \mathrm{~km}$ and $5 \mathrm{~km}$ ). Additionally, single dust layer is more often observed in a vertical column. Temporally, high amounts of dust aerosol (C-DAFOD as high as 0.08) experienced in spring subsequently continuous decrease until the spring of next year. The correlation coefficients between the latitude averaged column integrated dust aerosol feature optical depth (C-DAFOD) and precipitation, soil moisture, and vegetation coverage are $-0.65,-0.81$, and -0.77 , respectively. The correlation coefficients of seasonal mean C-DAFOD with the three factors are $-0.15,-0.67$, and -0.35 , respectively. The analysis showed dust and the other three factors are negatively correlated. Overall, dust over China shows considerable spatial, temporal, and vertical variations.
\end{abstract}

\section{Introduction}

Airborne dust is one of the largest sources of uncertainty in the radiative forcing and plays key roles in global climate change because of its complex direct and indirect effects on the state of atmosphere and underlying surfaces [1-5]. It has been identified that dust aerosol influences directly the energy budget and alters the cloud processes $[6,7]$. Furthermore, dust aerosol can also significantly affect the precipitation redistribution, reduce atmospheric visibility, and have adverse health effects [8-12]. Considering the severe impacts caused by dust aerosol, understanding its variation characteristics on earth, especially in regions with higher concentration of them, becomes increasingly essential for various scientific fields, such as climate change, hydrological cycle, ocean biogeochemistry, and air quality.

Use of satellite observations is the most efficient way to monitor aerosols on regional or even global scales [13]. Among the many satellite measurements, radiance from passive instruments [14-19], such as Total Ozone Mapping Spectrometer (TOMS), Ozone Monitoring Instrument
(OMI), Multiangle Imaging SpectroRadiometer (MISR), and Moderate Resolution Imaging Spectroradiometer (MODIS), has been exclusively used in acquiring dust variation characteristics over the past decade. Prospero et al. (2002) using Aerosol Index (AI) derived from TOMS reported that the largest and most persistent sources of dust are mainly concentrated in the Northern Hemisphere [20]. Darmenova et al. (2005) investigated the characteristics of spring dust outbreaks over East Asia by combining TMOS and MODIS observations [21]. Li et al. (2009) successfully isolated the dust source regions in the spatial domain from $45^{\circ} \mathrm{S}$ to $45^{\circ} \mathrm{N}$ and $180^{\circ} \mathrm{W}$ to $180^{\circ} \mathrm{E}$ by using a long-term TMOS and OMI AI data records [22]. Ginoux et al. (2012) presented a global-scale map of dust sources based on MODIS estimates of aerosol optical depth in conjunction with auxiliary datasets [23]. Ge et al. (2014) investigated the variation patterns of dust in Taklimakan Desert of China using the aerosol optical depth and Ångström exponent retrieved from MISR [24]. Xu et al. (2015) present a detailed analysis of the spatiotemporal variability in dust observed over northern China by combining OMI and MODIS satellite instruments observations 
[25]. However, due to the lack of ability in acquisition of aerosol vertical structure, above-mentioned passive sensors can only provide the column integral information of aerosols in horizontal. Recently, with the launch of CALIPSO satellite in April 2006, radiance data collected by the active sensor of Cloud Aerosol Lidar with Orthogonal Polarization (CALIOP) became available [26]. Compared with passive sensors, it can obtain profile of clouds and aerosols in high resolution, providing us with an unparalleled chance to study them in a three-dimensional perspective. For instance, by using CALIOP observations, Huang et al. [27] found that Asian dust occasionally extended as high as $9 \mathrm{~km}$ in altitude. Uno et al. [28] and Yang et al. [29] investigated the spatial and vertical distribution of airborne dust during its long-range transport based on aerosol profiles retrieved from CALIOP. A recent research performed by Huang et al. [30] examined the most probable heights of global cloud and aerosol layers through CALIOP.

China, located in East Asia, on the west coast of the Pacific Ocean, is the largest developing country in the world, comprising about $6.7 \%$ and $22 \%$ of the world's total land area and human population, respectively. From west to east across China, abundant dust activities occur annually over the arid and semiarid areas [31-34]. Due to dramatic increases in large scale farming and urbanization over past decades [35], China has gained a lot of attention and is considered as one of the major Asian dust sources. In our study reported herein, dust aerosol over China is investigated based on the A-Train (from Afternoon Train) CALIOP instrument during the period from 2007 to 2014. The aim of this investigation is to capture its variation patterns over China in last decade. The results of this study are useful to understand regional aerosol characteristic and compare aerosol climate models. This paper is structured as follows: Section 2 briefly describes the dataset used in this study; a detailed analysis of dust aerosol over China is conducted in Section 3; at last, the conclusions are drawn in Section 4.

\section{Data}

2.1. CALIOP Instrument. The CALIOP is a space-based lidar on board the CALIPSO platform launched in April 2006, which is designed to perform the measurements of the vertical structure of clouds and aerosols [26]. As a part of the A-Train constellation of satellites, CALIPSO follows the same ground track to other A-Train sensors and intends to complement current measurements and improves our understanding of weather and climate. CALIOP is a 3-degree off-nadir sensor (orbit period is 16 days) which transmits and receives backscattered light at two laser wavelengths of $532 \mathrm{~nm}$ (two polarization channels measure the degree of linear depolarization of the return signal) and $1064 \mathrm{~nm}$ (one channel measuring the total return signal) with a resolution of $333 \mathrm{~m}$ in the horizontal and $30 \mathrm{~m}$ in the vertical. By the joint use of these measuring signals, the vertical distribution of aerosols and clouds along with their microphysical and optical properties are simultaneously retrieved. With nearly ten years of data coverage, the CALIOP observations provide us with a valuable chance to study the variability of global aerosols.

2.2. CALIOP Level-2 Aerosol Layer Product. The CALIOP aerosol layer product (level-2) basically contains two tightly coupled data types. The first one is a set of column properties, which describe the temporal and spatial location of the vertical column atmosphere being sampled, such as the latitude and longitude. For each set of column properties, there is an associated set of layer properties, which specify the physical and optical characteristics of each detected feature, such as the layer altitude and aerosol type. The horizontal resolution of a single level-2 aerosol layer profile is $5 \mathrm{~km}$, and a maximum of 8 layers is populated in the profile vertically. The level-2 aerosol layer processing algorithms generally include the following steps [36-38]: firstly, the features (i.e., clouds, aerosols, and surface) are detected through the layer detection algorithm; then, the layer optical properties (i.e., mean values of the $532 \mathrm{~nm}$ and $1064 \mathrm{~nm}$ attenuated backscatter and attenuated total color ratio) and some other physical properties (i.e., top and base heights, latitude, and longitude) are computed for each detected layer; at last, each atmospheric aerosol feature (i.e., subtype, column, or layer aerosol optical depth) is acquired after the Cloud Aerosol Discrimination (CAD). More information on CALIOP and its aerosol products is given in Atmospheric Science Data Center website (ASDC, http://www-calipso.larc.nasa.gov/).

2.3. Data Preprocessing. The main datasets used for this study are the CAD score, Feature Classification Flag (FCF), and aerosol feature optical depth (AFOD) at $532 \mathrm{~nm}$ from the CALIOP level-2 aerosol layer product (Version 3) during the period from January 2007 to December 2014. In order to obtain high quality data and results, three steps of data screening are applied to the layer product: firstly, the daytime data are removed from the whole dataset. This is because noise from sunlight greatly interferes with its ability to accurately identify and retrieval aerosols. Then, a strict CAD score between -100 and -70 is used to further screen the result of erroneous layer detection triggered by noise [30], such as the lower aerosol layers contaminated by signals from the near surface. The CAD score is an integer value ranging from -100 to 100 that calculated from a multidimensional probability density function based approach to separating cloud from aerosol (negative value for aerosol and positive value for cloud). The absolute value of the CAD score represents the confidence level of cloud and aerosol discrimination: the larger the magnitude of the CAD score, the higher the confidence of the discrimination. Moreover, if a detected layer is flagged as aerosol, the aerosol subtype of this layer is then further classified into six categories, including clean marine, clean continental, polluted continental, desert dust (represents the elevated pure mineral soil), smoke, and polluted dust (represents the mixture of dust with any other kinds of aerosol), according to its attributes [39] and the result of that is recorded in the FCF dataset within the level-2 aerosol layer product. Therefore, in the selected layer data, the aerosol subtype from FCF dataset identified as desert dust (subtype code equals 2; the polluted dust layer is excluded in our 
study to reduce the contamination of other types of aerosol in the dust) is included in the final selection. As evaluated by Burton et al. (2013) [40], more than $80 \%$ of the CALIOP detected desert dust aerosol layers are basically correct and consistent with the results derived from the airborne High Spectral Resolution Lidar (HSRL-1) experiment conduct by NASA Langley Research Center (LaRC).

After the critical data screening, the AFOD of Dust (DAFOD) along with its column integrated value (CDAFOD, calculated by adding all the detected dust aerosol feature optical depth within a single profile) are used as the main indicators to demonstrate and analyze the vertical and spatiotemporal variation patterns of dust over China. The comparison between CALIOP level-2 aerosol optical depth and the result of that derived from MODIS (Moderate Resolution Imaging Spectroradiometer) and ground-based sun-photometer is quite well as in the ASDC website and Zong et al. (2015) [41]. Prior to the analysis, each of the CDAFOD and DAFOD are projected to an individual uniform grid. Since CALIOP is a nadir only sensor with a 16 -day repeat cycle, a 1.5 by 1.0 degrees uniform grid is used to reveal the spatial distribution patterns of C-DAFOD (there will be many gaps in the projected map, if we use a finer resolution grid). The vertical interval for the DAFOD grid is $500 \mathrm{~m}$. The monthly, seasonal, and multiyear averaged C-DAFOD and DAFOD data used in this study are calculated from daily measurements by dividing the total value of each of them per grid cell and time interval by the total number of satellite observation days instead of dust detected days to avoid the emergence of the abnormal hot-spot values.

2.4. Auxiliary Data. The monthly mean soil moisture height (SMH) and observed monthly total precipitation (MTP) dataset over China together with the monthly mean Normalized Difference Vegetation Index (NDVI) are investigated in this research because their changes are critical for analyzing variations in airborne dust. Specifically, the monthly mean soil moisture height (unit: $\mathrm{mm}$ ) dataset (Version 7) is calculated from the US Climate Prediction Center (CPC) [42], while the monthly total precipitation (unit: $\mathrm{mm}$ ) dataset (Version 2) is produced from the Global Precipitation Climatology Centre (GPCC) based on 67200 worldwide groundbased stations [43]. The NDVI dataset (MYD13C2 Version 005) derived from MODIS observations has been extensively used as an indicator of vegetation activity [44]. Its value is calculated from atmospherically corrected reflectance in the red- and near-infrared bands. Generally, for surfaces covered with dense vegetation, the NDVI tends to have values close to 1.0. However, for surfaces with little vegetation cover or no vegetation cover, the NDVI values tend to be low or even negative. The spatial resolutions of the used MSH, MTP, and NDVI are $0.5^{\circ}$ by $0.5^{\circ}, 1.0^{\circ}$ by $1.0^{\circ}$, and $0.05^{\circ}$ by $0.05^{\circ}$, respectively.

\section{Results and Discussion}

3.1. Spatial Distribution. To understand the spatial variability in dust observed over China, we divided all the detected dust profiles into three categories depending on the daily value of C-DAFOD: heavy dust loading (or dust storm) event (C-DAFOD greater than 1.0), high dust loading event (CDAFOD between 0.5 and 1.0), and light (or moderate) dust loading event (C-DAFOD between 0 and 0.5).

Figure 1 shows the spatial distribution maps (1.5 by 1.0 degrees) of the 8-year total number of dust occurrence days over China for above three different categories. As evidently presented in Figure 1, dust events over China tend to be lower in the south and east regions than those observed in the north and west regions. More specifically, it is obvious to see that all the heavy (or dust storm) (Figure 1(a)), high (Figure 1(b)), and light (or moderate) (Figure 1(c)) dust loading events mostly occur in northwestern China, with the highest occurrence regions being generally defined at the Taklimakan Desert of southern Xinjiang province. In Figure 1(a), heavy dust loading days in the Taklimakan Desert are significantly greater than those observed over any other regions of China, revealing that this area is the most intense dusty region in China. Actually, Taklimakan Desert is a basin structure (known as Tarim Basin) with highlands on three sides (the Mongolian Plateau to the north, the Pamir Plateau to the west, and the Tibetan Plateau to the south), which tend to produce favorable conditions for dust outbreak $[34,45]$ and make Taklimakan Desert one of the largest global sources of atmospheric dust. Figure 1(b) shows that the coverage of the high dust loading event is larger than heavy dust loading event and a long belt of high dust occurrence region starting westward from the Taklimakan Desert in southern Xinjiang province, passing through the Qinghai, Gansu, Ningxia, Neimenggu, Shanxi, and Shaanxi provinces, and reaching to the eastern coastal areas such as the capital surrounding (e.g., Hebei, Henan, and Shandong) and lowlatitude Yangtze River (e.g., Jiangsu and Anhui) areas were detected. This long dusty belt in fact depicts the major dustaffected regions in China and is basically consistent with the most prevailing dust transport path of China (the red dashed line depicted in Figure 1) reported by Shao et al. (2006) [46]. In Figure 1(c), it is evidently seen by comparing Figures $1(\mathrm{a})$ and $1(\mathrm{~b})$ that the occurrence of light and moderate dust loading activities over China are significantly higher than that of the high and heavy dust loading activities. Moreover, it can be easily identified that light and moderate dust loading activities can be frequently observed over nearly all the areas of China, demonstrating that China is a country polluted widely by airborne dust. Another remarkable point acquired from Figure 1 is that the lowest dust occurrence region is mainly presented in the remote northeast and southwest part of China, where all the three kinds of dust events are rarely observed.

Figures 2(a)-2(d) show the 8-year averaged spatial distribution of the C-DAFOD (Figure 2(a)), MTP (Figure 2(b)), SMH (Figure 2(c)), and NDVI (Figure 2(d)) over China. As shown in these figures, high C-DAFOD areas generally correspond to regions with low MTP, SMH, and NDVI values. Specifically, the multiyear averaged C-DAFOD values observed over southeastern China are generally below 0.003 , whereas the multiyear averaged MTP, SMH, and NDVI values in these areas are as high as $200 \mathrm{~mm}, 600 \mathrm{~mm}$, and 0.8 , respectively. However, the multiyear averaged C-DAFOD 


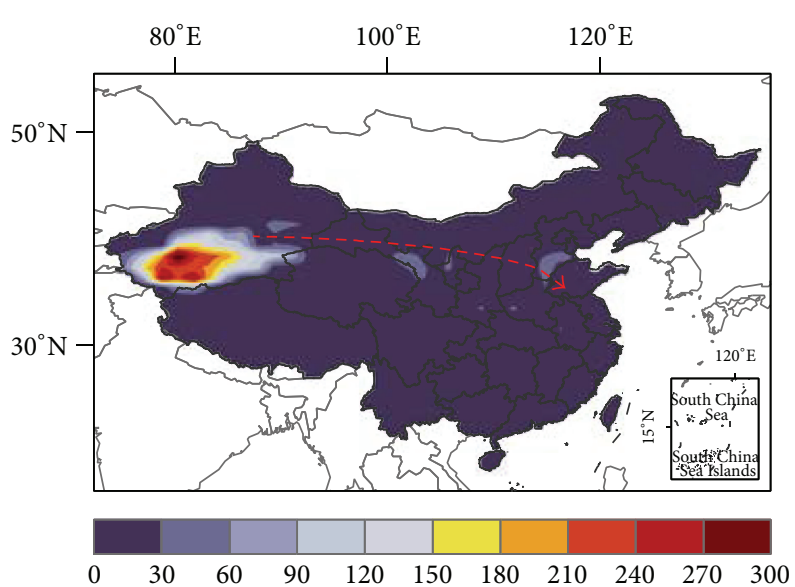

(a)

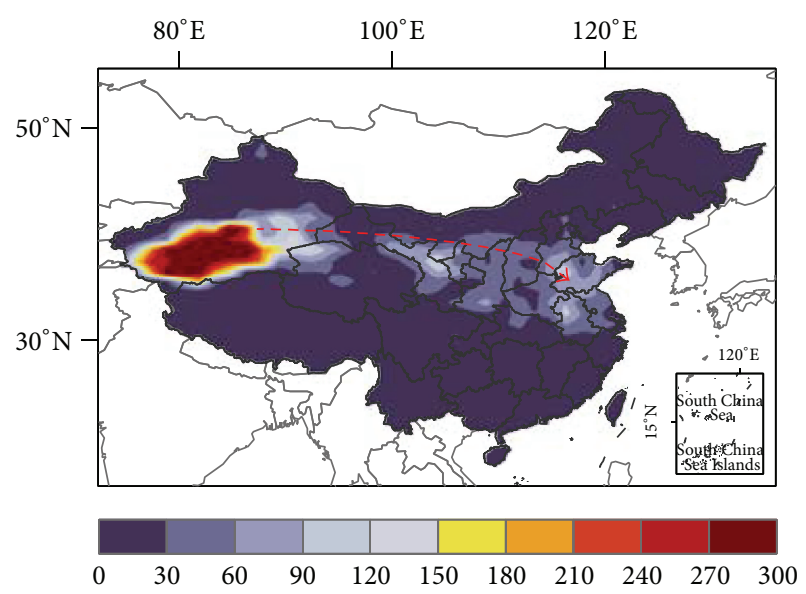

(b)

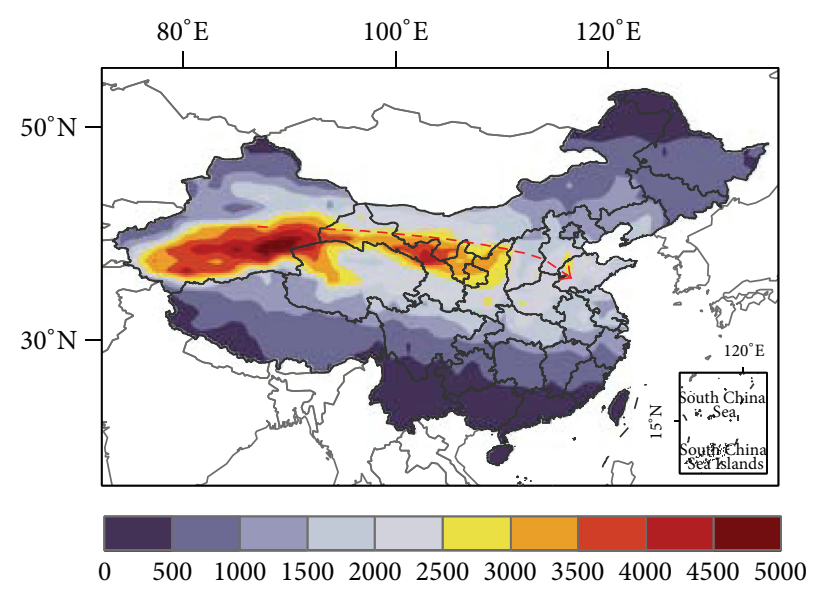

(c)

FIGURE 1: Spatial distribution maps of 8-year (2007-2014) total occurrence days of dust over China as observed from CALIOP. (a) Heavy dust loading (or dust storm) event. (b) High dust loading event. (c) Light (or moderate) dust loading event. Red dashed line represents the most prevailing dust transport path of China.

values observed over northwestern China are nearly more than ten times higher than those observed over southeastern China, whereas the multiyear averaged MTP, SMH, and NDVI values in northwestern China are significantly lower than those of the southeastern China. Moreover, as shown in Figure 2(e), the MTP, SMH, and NDVI exhibit a reverse spatial variation pattern compared with the variation in dust aerosol from west to east across China. The C-DAFOD shows a negative variation from west to east, while the opposite behaviors are obtained from the other three parameters. The correlation coefficients between the latitude averaged CDAFOD and the MTP, SMH, and NDVI are $-0.65,-0.81$, and -0.77 , respectively. These observed results along with the spatial distribution maps of the four factors reveal that the spatial pattern of dust over China is negatively linked to precipitation and soil moisture as well as vegetation coverage. In fact, far from the Pacific Ocean, northwestern China has significantly lower moisture than the average in China. This lack of moisture leads to an extreme lack of precipitation, dry soil, and reduced plant life; thus, many areas become large deserts and provide abundant loose particles for dust emission. However, closer to the Pacific Ocean, moisture from the ocean provides more precipitation to southeastern than to northwestern China. This helps to enhance soil moisture, vitalize the vegetation, and prevent soil erosion. Consequently, more dust events are detected over the northwest instead of the southeast part of China. The expected opposite behavior of dust presence and the other three parameters in Figure 2 also support the reliability of used satellite based data.

3.2. Temporal Variation. In this section, the temporal variability in dust over China is analyzed. Figure 3 summarizes the seasonal mean maps of the C-DAFOD over China. Overall, China experiences higher amounts of dust in spring and lower amounts of that in the other seasons. In winter (December, January, and February), the C-DAFOD values over China are generally low except for the long dusty belt regions. Under the influences of spring cyclonic activities and cold surges that emerge from Siberia [46-48], high CDAFOD values begin to disperse from the dusty belt to 


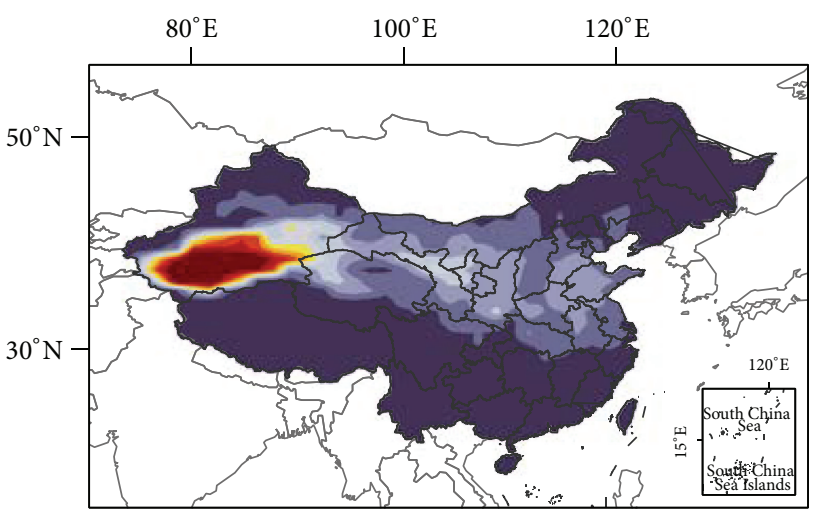

$\begin{array}{lllllllllll}0.000 & 0.003 & 0.006 & 0.009 & 0.012 & 0.015 & 0.018 & 0.021 & 0.024 & 0.027 & 0.030\end{array}$

(a)

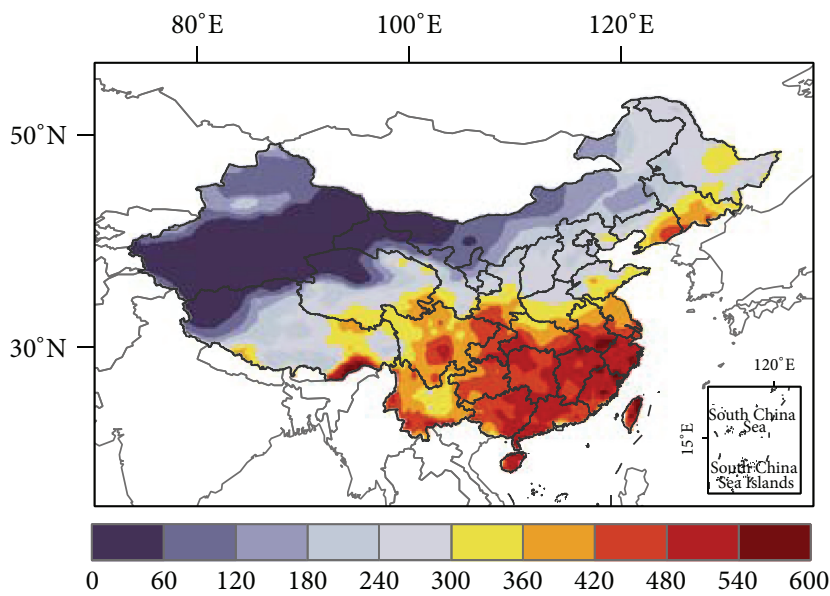

(c)

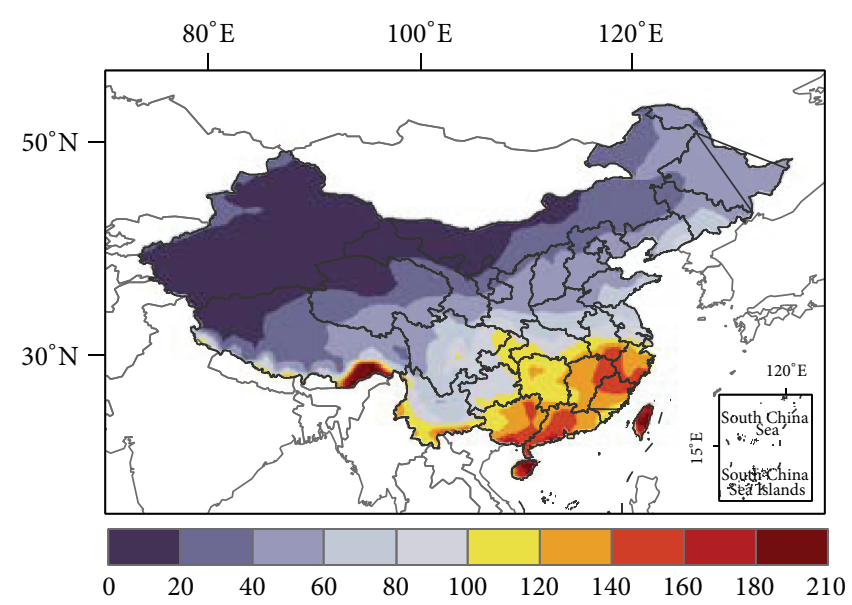

(b)

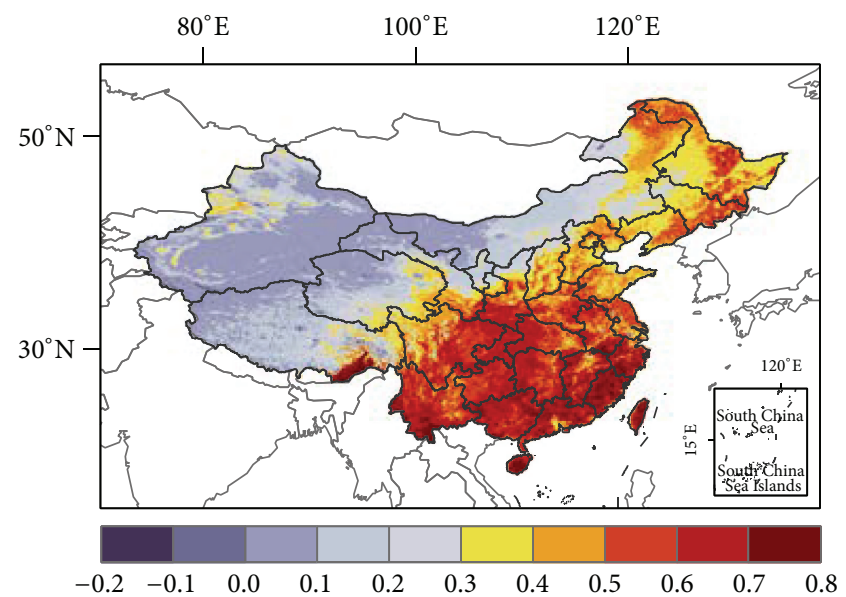

(d)

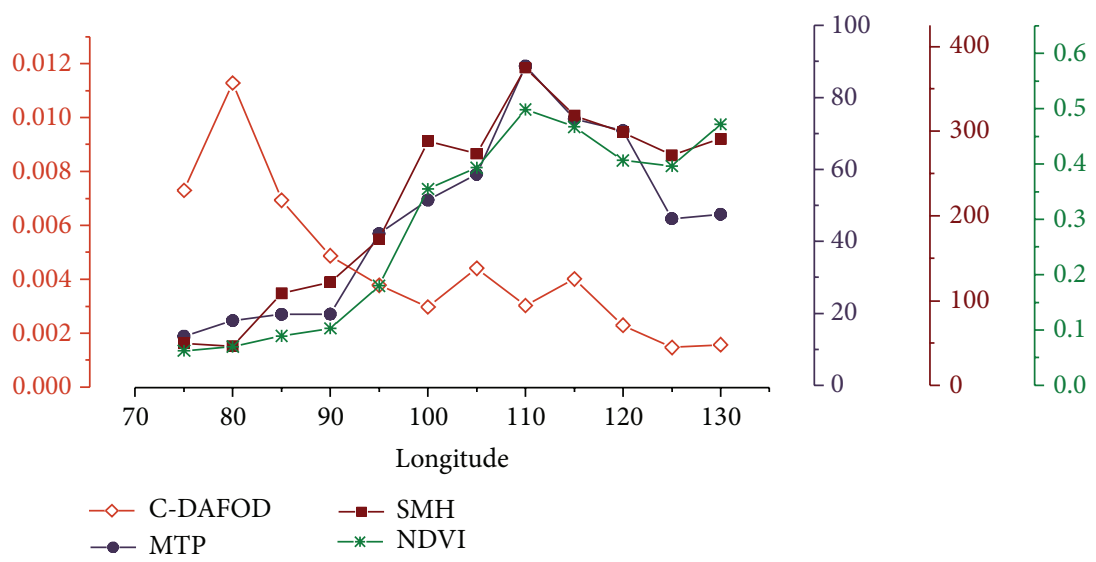

(e)

Figure 2: Spatial distribution maps of the multiyear (2007-2014) averaged (a) C-DAFOD, (b) MTP, (c) SMH, and (d) NDVI over China. (e) Longitudinal variation of the latitude averaged values for the previous four maps.

most of the northern as well as the eastern coastal areas of China, especially in the Taklimakan Desert region of southern Sinkiang province. From summer onward, the CDAFOD continuously decreases until the spring of next year, with the most distinct reduction detected over eastern and southern China. To further understand the temporal variation features of dust over China, the intra-annual variability in the C-DAFOD along with the MTP, SMH, and NDVI values is analyzed based on the multiyear monthly averaged observations. 


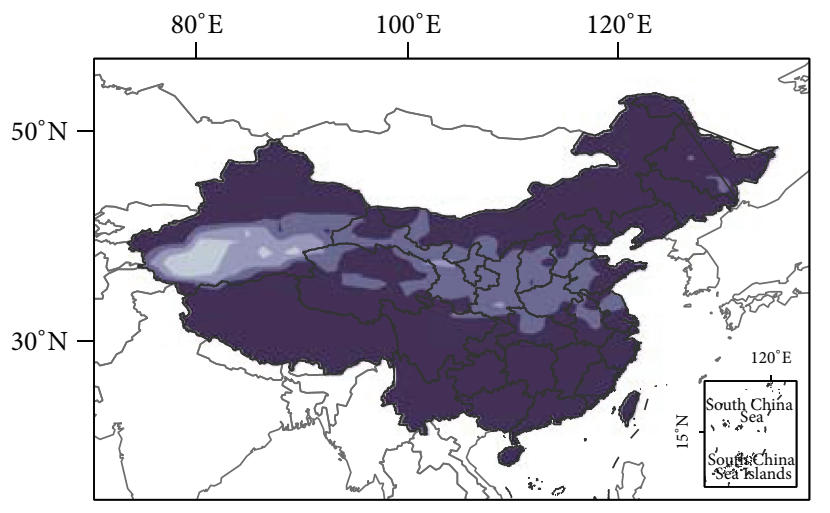

$\begin{array}{lllllllllll}0.000 & 0.005 & 0.010 & 0.015 & 0.020 & 0.025 & 0.030 & 0.035 & 0.040 & 0.045 & 0.050\end{array}$

(a)

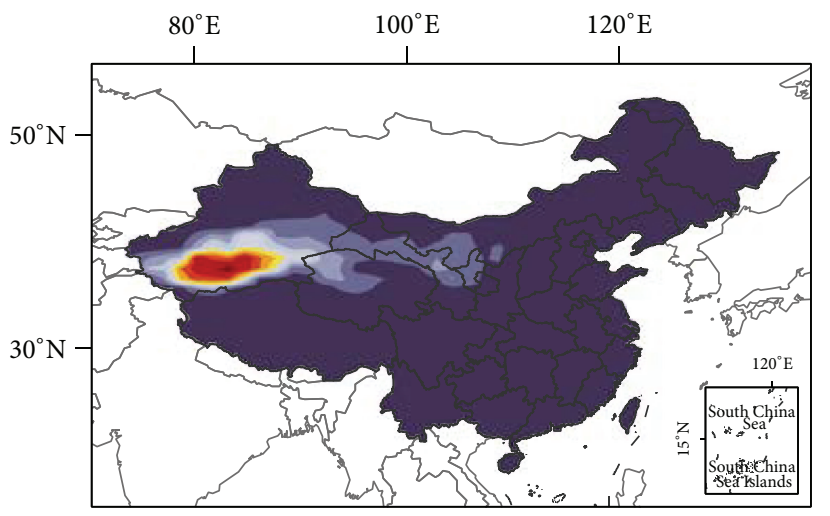

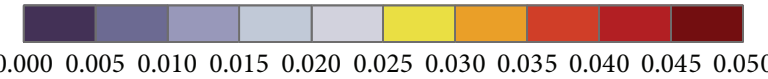

(c)

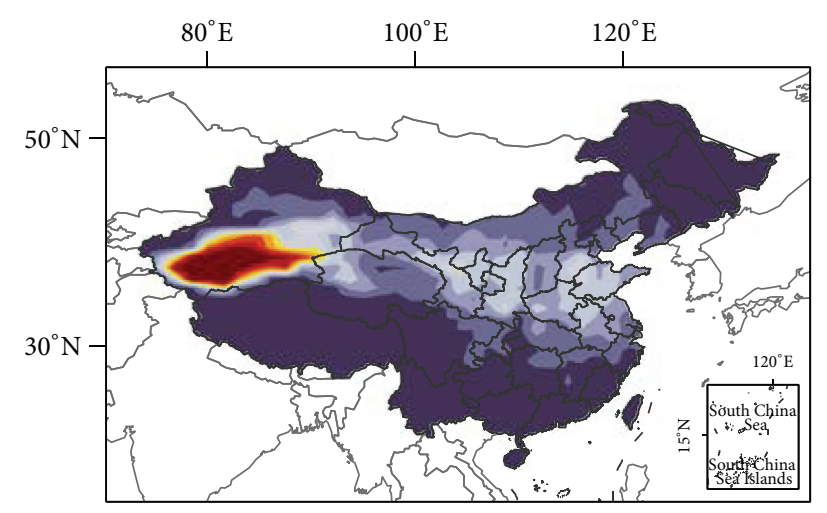

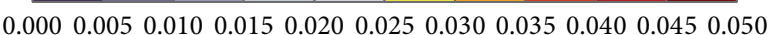

(b)

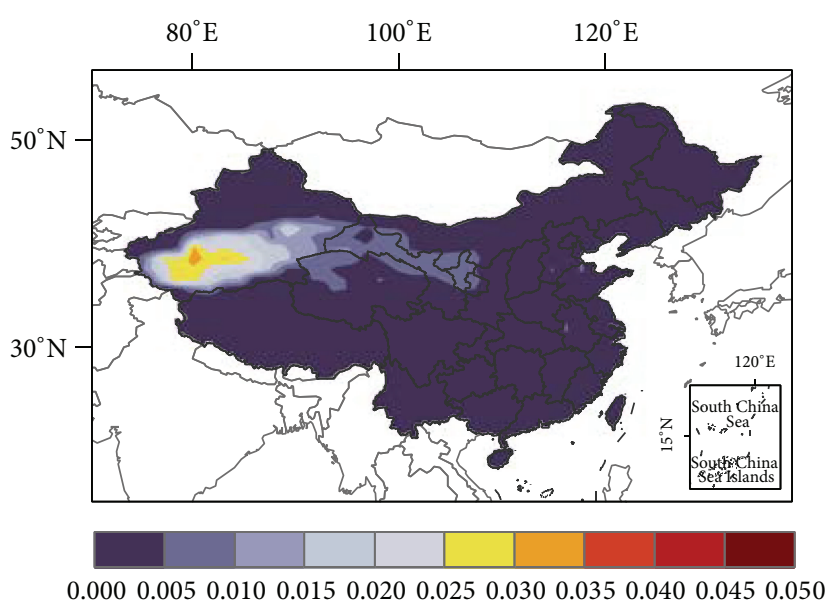

(d)

Figure 3: Seasonal mean spatial distribution maps of the C-DAFOD over China from 2007 to 2014. (a) Winter, (b) spring, (c) summer, and (d) autumn.

As shown in Figure 4, the C-DAFOD values lie in a wide range (as low as 0.002 up to 0.008 in certain cases), with a mean of $0.0043 \pm 0.002$. More specifically, distinct maximum C-DAFOD values were systematically observed in spring, with the highest value in April (not shown). Then, the dust aerosol weakens rapidly in summer. Subsequently, the C-DAFOD values are stabilized in a low level over the next two seasons. Despite the significant intra-annual variability, the trend in C-DAFOD values in the examined period is absent (the linear fit is $Y_{\mathrm{C} \text {-DAFOD }}=-3.1 e^{-8} * X_{\text {year }}+0.08$ ). Such a negligible trend demonstrates that the amounts of dust aerosol over China, as a matter of fact, have little changes during the past few years.

The MTP and NDVI time series display a generally consistent temporal variation pattern, with maximum in summer when the Asian monsoon transports large amounts of water vapor to China. The increasing precipitation and vegetation in summer may clean the suspended airborne dust, conserve the water and soil, and also reduce the wind speed, which in turn lead to a sharp declined dust outbreak. The peak SMH values are observed mainly in the time period of autumn which is about three months later to that observed for MTP and NDVI. The correlation coefficients between the seasonal mean C-DAFOD and the MTP, SMH, and NDVI are $-0.15,-0.67$, and -0.35 , respectively, which suggests that the C-DAFOD time series is negatively correlated with the MTP and NDVI as well as the SMH. Moreover, the spatial (as shown in Section 3.1) and temporal variations highly consistent between C-DAFOD and SMH imply that soil moisture may be the most direct governor to the occurrence of dust among the discussed three factors.

\section{Vertical Profile}

Figure 5 presents the multiyear averaged DAFOD profile over China during the period from 2007 to 2014 and several interesting points can be clearly identified from it. As shown in Figure 5(a), the dust layers are usually distributed across the atmosphere up to $5 \mathrm{~km}$. Larger DAFOD layers are primarily at the altitudes of $1.5 \mathrm{~km}$ to $4.5 \mathrm{~km}$, with $95 \%$ of the column integrated DAFOD being observed in this interval. In particular, the maximum DAFOD layer is at around $3 \mathrm{~km}$ 


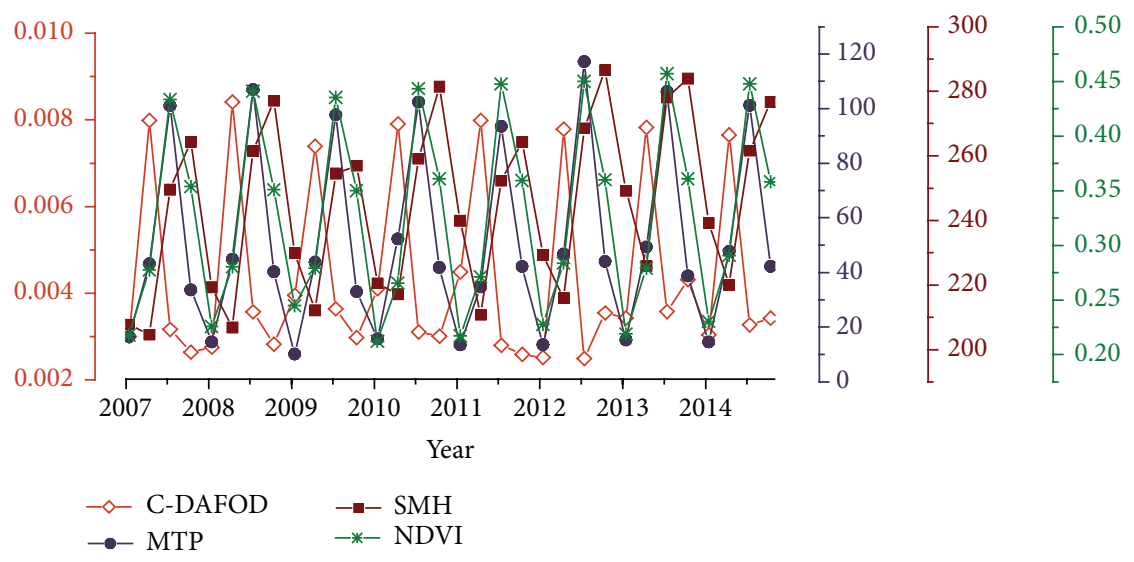

FIgURE 4: The interannual variability in the C-DAFOD, MTP, SMH, and NDVI as obtained from the multiyear seasonal mean observations over China (all the grid cells in the area of China are used in the calculation of average) from 2007 to 2014.

vertically, which suggests that the lofted dust particles over China more often stay afloat at this altitude.

Another remarkable point acquired from Figure 5 is that there is a significant seasonal drifting of the position of dust layer over China. As shown in Figure 5(b), larger DAFOD values appear near the altitude of $2.5 \mathrm{~km}$ in spring when dust occurs most frequently in China. Additionally, in that season, dust layers have a larger vertical coverage and can reach up to as high as $6 \mathrm{~km}$ in altitude, which is consistent with the result reported by Huang et al. (2007) [49]. In summer, the maximum DAFOD layers are generally observed at $3 \mathrm{~km}$, but the values of those have significantly decreased. From autumn to winter, when the dust generation and lofting are less active over China, dust layers are basically distributed below $3 \mathrm{~km}$ and exhibit a smaller geometrical layer thickness. Ge et al. (2014) [24] also found that the dust layers in spring and summer are much higher than the other two seasons in northwestern China. The maximum DAFOD layer altitudes generally decreased in order of summer, spring, autumn, and winter, as the quadrangle line depicted in Figure 5(b). Actually, massive coarse and large dust particles generated in spring are mostly suspended in the lower atmosphere. Along with the atmospheric transport, the fine dust particles can extend to a higher altitude in summer. During autumn and winter, under the influence of gravitational settling or some other atmospheric activities, such as the convective motion, dust aerosol is generally located at the boundary layer. In general, the seasonal variation of the dust layer altitude is not identical with that observed for intensity (C-DAFOD).

To discern changes in dust properties during transport, we examine dust behavior in the two regions. The first one is located within the Taklimakan dust source area (DS, from $36.5^{\circ} \mathrm{S}$ to $40.5^{\circ} \mathrm{N}$ and $79.5^{\circ} \mathrm{W}$ to $83.5^{\circ} \mathrm{E}$ ), where the most widespread heavy dust activities are observed. The second one is far away from the source in the capital surrounding area of eastern China (CS, from $33.5^{\circ} \mathrm{S}$ to $37.5^{\circ} \mathrm{N}$ and $114^{\circ} \mathrm{W}$ to $118^{\circ} \mathrm{E}$ ), where the airborne dust originated from northwest part is frequently transported to this area. As shown in Figure 5(c), the vertical distribution of dust layers over the two selected regions is not identical. In the DS region, most of the airborne dust is between $1.5 \mathrm{~km}$ and $5 \mathrm{~km}$ altitude, with the peak DAFOD value around $3 \mathrm{~km}$. This elevated dust distribution is a typical result of the source area. However, in the CS region, airborne dust is rarely found above $4 \mathrm{~km}$, and the peak DAFOD layer is suspended in the altitude of $1.5 \mathrm{~km}$, which is obviously lower than the value observed over the DS region. This change in the vertical distribution implies that the meteorological conditions in region CS are different from those of the DS region. Moreover, gravitational settling also plays a key role in the vertical distribution of dust during its transport.

Many of the previous studies make an assumption of single layer structure in their dust retrieval algorithms [50, 51]. However, it is unclear whether the assumption is reasonable or not. Figure 6 presents the percentage of vertical column total dust layer numbers found in each of the CALIOP profiles over China during the period from 2007 to 2014. For convenience, the vertical column total dust layer numbers were classified as three categories: aerosol layers $=1$, aerosol layers $=2$, and aerosol layers $\geq 3$. It has been noticed that single layer is the most dominant part in the examined dust profiles. More than $50 \%$ of the total profiles are featured as single dust layer structure. The percentage for two dust layers that coexists in a vertical column is still as high as $30 \%$. Compared to single and two-layer structures, the proportions for three (or more) coexisting dust layers are insignificant, only about $10 \%$. This result suggests that the assumption of single layer structure in the dust retrieval algorithms is generally correct. However, two layers coexisting condition also should be considered in the dust model, which will greatly benefit the retrievals.

\section{Conclusion}

A better understanding of the regional spatial and vertical distributions of aerosol is particularly useful not only for improving the accuracy of satellite aerosol retrievals but also for monitoring aerosol transport and comparing climate 


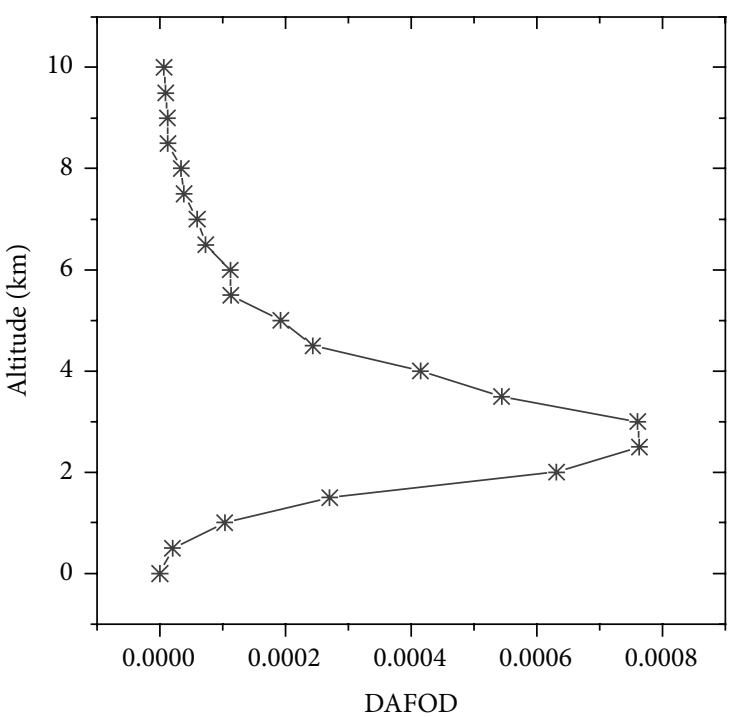

(a)

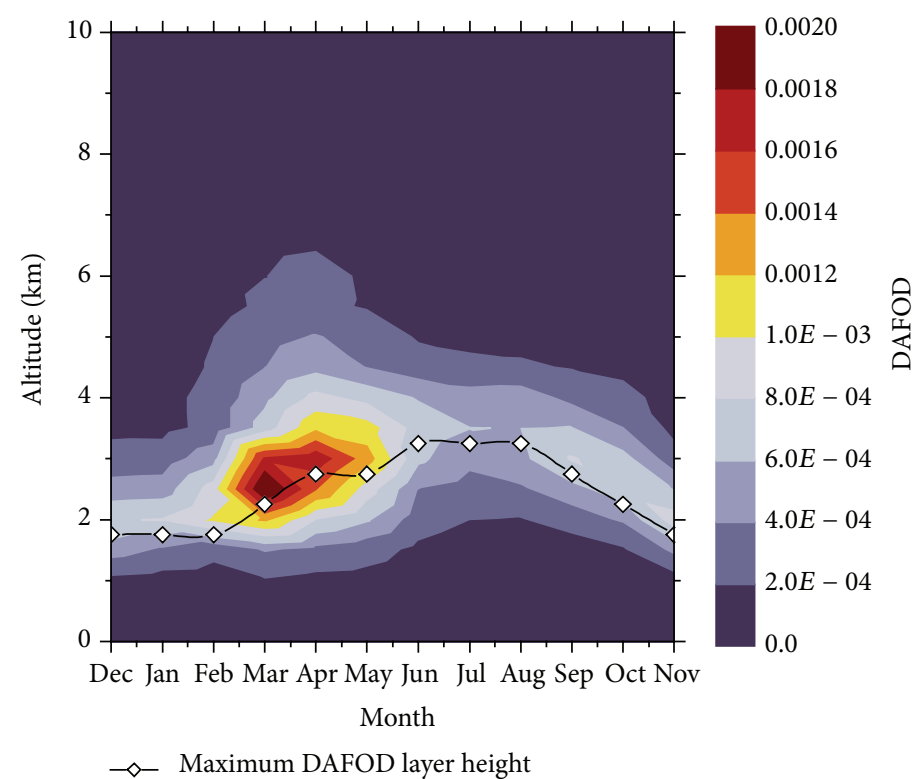

(b)

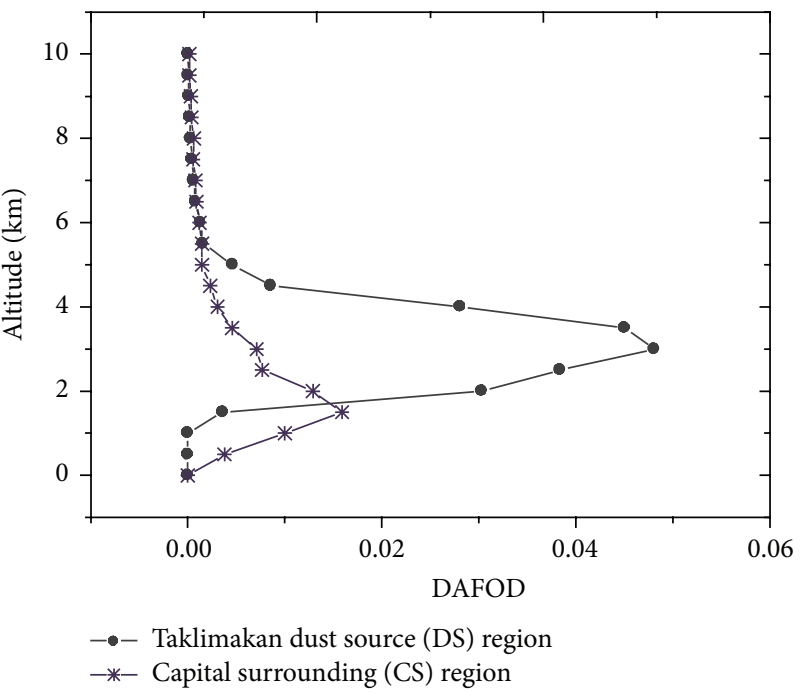

(c)

FIgURE 5: The (a) multiyear averaged DAFOD profile along with its (b) intra-annual variation pattern over China as measured by CALIOP from 2007 to 2014. The black quadrangle line shows the monthly mean vertical maximum DAFOD layer altitude. (c) The comparison of the multiyear averaged DAFOD profile between Taklimakan dust source and capital surrounding (far away from the source region) areas of China.

models. In this work, variability in dust over China is analyzed using CALIOP lidar instrument. The main conclusions drawn from the analysis can be summarized as follows:

(1) The spatial distribution of dust aerosol over China typically has geographical features. In general, the amounts of dust aerosol are relatively higher in the north than in the south areas of China, and airborne dust concentrations over China also tend to be lower in the east regions than in the west regions. The largest aerosol loading center is located in Taklimakan Desert, where frequent dust activities are observed. Moreover, the spatial distribution of airborne dust is opposite to the distribution of precipitation, soil moisture, and vegetation coverage, which implies that these three factors are essential to the spatial pattern of dust over China.

(2) The whole China territory experienced higher amounts of dust in spring (with highest in April) and lower amounts of that in the other seasons. The multiyear time series of airborne dust reveals that dust aerosol over China has little changes during the past ten years. In addition, the temporal variation of airborne dust over China is observed negatively correlated with precipitation, soil moisture, and 


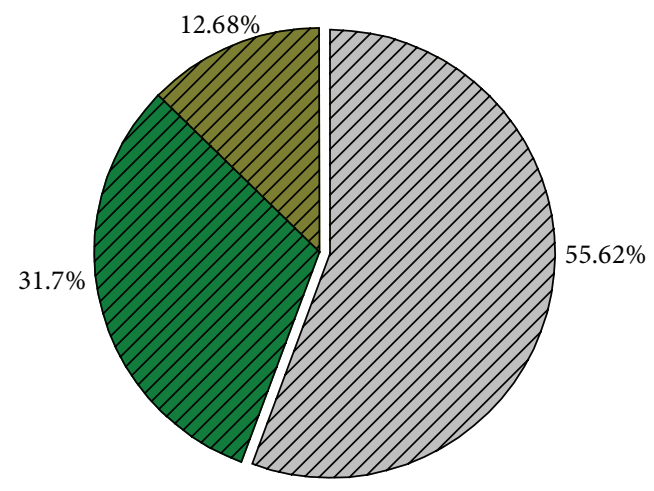

DID Aerosol layer $=1$
DDA Aerosol layer $=2$
DDA Aerosol layer $\geq 3$

FIgURE 6: The percentage of vertical column total dust aerosol layer numbers identified from each of the CALIOP profiles over China during the period from 2007 to 2014.

vegetation coverage. Furthermore, higher negative correlation between soil moisture and dust aerosol suggests that soil moisture may more directly be linked to dust activity.

(3) Airborne dust over China is mostly distributed across the atmosphere up to $5 \mathrm{~km}$, with the peak dust loading layers are observed at the altitudes around $3 \mathrm{~km}$. Moreover, the altitude of dust layer is higher in spring and summer and also in the dust source areas. This layer drafting phenomenon is associated with atmospheric transport, gravitational settling, and some other factors. Besides, it has also been noted that dust over China primarily exist in the form of single layer structure.

\section{Competing Interests}

The authors declare that there are no competing interests regarding the publication of this paper.

\section{Authors' Contributions}

All authors assisted in the analyzing and editing of the paper. $\mathrm{Hui} \mathrm{Xu}$ is the main author who processed the data, analyzed the results, and wrote the paper.

\section{Acknowledgments}

This study is funded by the National Natural Science Foundation of China (nos. 41401422 and 41501404) and the China High Resolution Earth Observation Project (no. Y6D0060038). The authors acknowledge the data support from NASA and NOAA.

\section{References}

[1] J. Haywood and O. Boucher, "Estimates of the direct and indirect radiative forcing due to tropospheric aerosols: a review," Reviews of Geophysics, vol. 38, no. 4, pp. 513-543, 2000.
[2] Z. Levin, E. Ganor, and V. Gladstein, "The effects of desert particles coated with sulfate on rain formation in the eastern Mediterranean," Journal of Applied Meteorology, vol. 35, no. 9, pp. 1511-1523, 1996.

[3] I. N. Sokolik, D. M. Winker, G. Bergametti et al., "Introduction to special section: outstanding problems in quantifying the radiative impacts of mineral dust," Journal of Geophysical Research Atmospheres, vol. 106, no. 16, pp. 18015-18027, 2001.

[4] J. Huang, Y. Wang, T. Wang, and Y. Yi, "Dusty cloud radiative forcing derived from satellite data for middle latitude regions of East Asia," Progress in Natural Science: Materials International, vol. 16, no. 10, pp. 1084-1089, 2006.

[5] R. L. Miller and I. Tegen, "Climate response to soil dust aerosols," Journal of Climate, vol. 11, no. 12, pp. 3247-3267, 1998.

[6] J. Huang, P. Minnis, B. Lin et al., "Possible influences of Asian dust aerosols on cloud properties and radiative forcing observed from MODIS and CERES," Geophysical Research Letters, vol. 33, no. 6, Article ID L06824, 2006.

[7] J. Huang, B. Lin, P. Minnis et al., "Satellite-based assessment of possible dust aerosols semi-direct effect on cloud water path over East Asia," Geophysical Research Letters, vol. 33, no. 19, Article ID L19802, 2006.

[8] J. P. Dunion and C. S. Velden, "The impact of the Saharan Air Layer on Atlantic tropical cyclone activity," Bulletin of the American Meteorological Society, vol. 85, no. 3, pp. 353-365, 2004.

[9] A. T. Evan, J. Dunion, J. A. Foley, A. K. Heidinger, and C. S. Velden, "New evidence for a relationship between Atlantic tropical cyclone activity and African dust outbreaks," Geophysical Research Letters, vol. 33, no. 19, Article ID L19813, 2006.

[10] W. J. Hui, B. I. Cook, S. Ravi, J. D. Fuentes, and P. D’Odorico, "Dust-rainfall feedbacks in the West African Sahel," Water Resources Research, vol. 44, no. 5, Article ID W05202, pp. 1-6, 2008.

[11] H.-J. Han, B.-J. Sohn, H.-L. Huang, E. Weisz, R. Saunders, and T. Takamura, "An improved radiance simulation for hyperspectral infrared remote sensing of Asian dust," Journal of Geophysical Research Atmospheres, vol. 117, no. 9, Article ID D09211, 2012.

[12] X. Yu, C. Shi, J. Ma et al., "Aerosol optical properties during firework, biomass burning and dust episodes in Beijing," Atmospheric Environment, vol. 81, pp. 475-484, 2013.

[13] K. H. Lee, Z. Q. Li, J. K. Young, and A. Kokhanovsky, "Atmospheric aerosol monitoring from satellite observations: a history of three decades," in Atmospheric and Biological Environmental Monitoring, pp. 13-38, Springer, Berlin, Germany, 2009.

[14] O. Torres, P. K. Bhartia, J. R. Herman, Z. Ahmad, and J. Gleason, "Derivation of aerosol properties from satellite measurements of backscattered ultraviolet radiation: theoretical basis," Journal of Geophysical Research Atmospheres, vol. 103, no. 14, pp. 17099$17110,1998$.

[15] O. Torres, A. Tanskanen, B. Veihelmann et al., "Aerosols and surface UV products form ozone monitoring instrument observations: an overview," Journal of Geophysical Research Atmospheres, vol. 112, no. 24, Article ID D24S47, 2007.

[16] O. Torres, C. Ahn, and Z. Chen, "Improvements to the OMI near-UV aerosol algorithm using A-train CALIOP and AIRS observations," Atmospheric Measurement Techniques, vol. 6, no. 11, pp. 3257-3270, 2013.

[17] D. J. Diner, J. C. Beckert, T. H. Reilly et al., "Multi-angle imaging spectroradiometer (MISR) instrument description and experiment overview," IEEE Transactions on Geoscience and Remote Sensing, vol. 36, no. 4, pp. 1072-1087, 1998. 
[18] N. C. Hsu, S.-C. Tsay, M. D. King, and J. R. Herman, "Aerosol properties over bright-reflecting source regions," IEEE Transactions on Geoscience and Remote Sensing, vol. 42, no. 3, pp. 557569, 2004.

[19] L. A. Remer, Y. J. Kaufman, D. Tanré et al., “The MODIS aerosol algorithm, products, and validation," Journal of the Atmospheric Sciences, vol. 62, no. 4, pp. 947-973, 2005.

[20] J. M. Prospero, P. Ginoux, O. Torres, S. E. Nicholson, and T. E. Gill, "Environmental characterization of global sources of atmospheric soil dust identified with the Nimbus 7 Total Ozone Mapping Spectrometer (TOMS) absorbing aerosol product," Reviews of Geophysics, vol. 40, no. 1, pp. 1-31, 2002.

[21] K. Darmenova, I. N. Sokolik, and A. Darmenov, "Characterization of east Asian dust outbreaks in the spring of 2001 using ground-based and satellite data," Journal of Geophysical Research D: Atmospheres, vol. 110, no. 2, pp. 1-18, 2005.

[22] J. Li, B. E. Carlson, and A. A. Lacis, "A study on the temporal and spatial variability of absorbing aerosols using Total Ozone Mapping Spectrometer and Ozone Monitoring Instrument Aerosol Index data," Journal of Geophysical Research Atmospheres, vol. 114, no. 9, Article ID D09213, 2009.

[23] P. Ginoux, J. M. Prospero, T. E. Gill, N. C. Hsu, and M. Zhao, "Global-scale attribution of anthropogenic and natural dust sources and their emission rates based on MODIS Deep Blue aerosol products," Reviews of Geophysics, vol. 50, no. 3, Article ID RG3005, 2012.

[24] J. M. Ge, J. P. Huang, C. P. Xu, Y. L. Qi, and Y. L. Liu, "Characteristics of Taklimakan dust emission and distribution: a satellite and reanalysis field perspective," Journal of Geophysical Research: Atmospheres, vol. 119, no. 20, pp. 11772-11783, 2014.

[25] H. Xu, T. Cheng, X. Gu, T. Yu, D. Xie, and F. Zheng, "Spatiotemporal variability in dust observed over the Sinkiang and Inner Mongolia regions of Northern China," Atmospheric Pollution Research, vol. 6, no. 4, pp. 562-571, 2015.

[26] D. M. Winker, W. H. Hunt, and M. J. McGill, "Initial performance assessment of CALIOP," Geophysical Research Letters, vol. 34, no. 19, Article ID L19803, 2007.

[27] J. Huang, P. Minnis, B. Chen et al., "Long-range transport and vertical structure of Asian dust from CALIPSO and surface measurements during PACDEX," Journal of Geophysical Research Atmospheres, vol. 113, no. 23, Article ID D23212, 2008.

[28] I. Uno, K. Eguchi, K. Yumimoto et al., "Asian dust transported one full circuit around theglobe," Nature Geoscience, vol. 2, no. 8, pp. 557-560, 2009.

[29] W. Yang, A. Marshak, T. Várnai, O. V. Kalashnikova, and A. B. Kostinski, "CALIPSO observations of transatlantic dust: vertical stratification and effect of clouds," Atmospheric Chemistry and Physics, vol. 12, no. 23, pp. 11339-11354, 2012.

[30] J. Huang, J. Guo, F. Wang et al., "CALIPSO inferred most probable heights of global dust and smoke layers," Journal of Geophysical Research D: Atmospheres, vol. 120, no. 10, pp. 50855100, 2015.

[31] X. Y. Zhang, R. Arimoto, and Z. S. An, "Dust emission from Chinese desert sources linked to variations in atmospheric circulation," Journal of Geophysical Research Atmospheres, vol. 102, no. 23, pp. 28041-28047, 1997.

[32] J. Xuan, G. Liu, and K. Du, "Dust emission inventory in Northern China," Atmospheric Environment, vol. 34, no. 26, pp. 4565-4570, 2000.

[33] L. Natsagdorj, D. Jugder, and Y. S. Chung, "Analysis of dust storms observed in Mongolia during 1937-1999," Atmospheric Environment, vol. 37, no. 9-10, pp. 1401-1411, 2003.
[34] X. Wang, J. Huang, M. Ji, and K. Higuchi, "Variability of East Asia dust events and their long-term trend," Atmospheric Environment, vol. 42, no. 13, pp. 3156-3165, 2008.

[35] J. H. Seinfeld, G. R. Carmichael, R. Arimoto et al., "ACE-ASIA: regional climatic and atmospheric chemical effects of asian dust and pollution," Bulletin of the American Meteorological Society, vol. 85, no. 3, pp. 367-380, 2004.

[36] D. M. Winker, M. A. Vaughan, A. Omar et al., "Overview of the CALIPSO mission and CALIOP data processing algorithms," Journal of Atmospheric and Oceanic Technology, vol. 26, no. 11, pp. 2310-2323, 2009.

[37] M. A. Vaughan, K. A. Powell, R. E. Kuehn et al., "Fully automated detection of cloud and aerosol layers in the CALIPSO lidar measurements," Journal of Atmospheric and Oceanic Technology, vol. 26, no. 10, pp. 2034-2050, 2009.

[38] Z. Liu, M. Vaughan, D. Winker et al., "The CALIPSO lidar cloud and aerosol discrimination: version 2 algorithm and initial assessment of performance," Journal of Atmospheric and Oceanic Technology, vol. 26, no. 7, pp. 1198-1213, 2009.

[39] A. H. Omar, D. M. Winker, C. Kittaka et al., "The CALIPSO automated aerosol classification and lidar ratio selection algorithm," Journal of Atmospheric and Oceanic Technology, vol. 26, no. 10, pp. 1994-2014, 2009.

[40] S. P. Burton, R. A. Ferrare, M. A. Vaughan et al., "Aerosol classification from airborne HSRL and comparisons with the CALIPSO vertical feature mask," Atmospheric Measurement Techniques, vol. 6, no. 5, pp. 1397-1412, 2013.

[41] X. M. Zong, X. X. Xia, and H. Z. Che, "Validation of aerosol optical depth and climatology of aerosol vertical distribution in the taklimakan desert," Atmospheric Pollution Research, vol. 6, no. 2, pp. 239-244, 2015.

[42] Y. Fan and H. van den Dool, "Climate Prediction Center global monthly soil moisture data set at $0.5^{\circ}$ resolution for 1948 to present," Journal of Geophysical Research D: Atmospheres, vol. 109, no. 10, Article ID D10102, 2004.

[43] U. Schneider, A. Becker, P. Finger, A. Meyer-Christoffer, M. Ziese, and B. Rudolf, "GPCC's new land surface precipitation climatology based on quality-controlled in situ data and its role in quantifying the global water cycle," Theoretical and Applied Climatology, vol. 115, no. 1, pp. 15-40, 2014.

[44] A. Huete, K. Didan, T. Miura, E. P. Rodriguez, X. Gao, and L. G. Ferreira, "Overview of the radiometric and biophysical performance of the MODIS vegetation indices," Remote Sensing of Environment, vol. 83, no. 1-2, pp. 195-213, 2002.

[45] J. Sun, M. Zhang, and T. Liu, "Spatial and temporal characteristics of dust storms in China and its surrounding regions, 1960-1999: relations to source area and climate," Journal of Geophysical Research Atmospheres, vol. 106, no. 10, Article ID 2000JD900665, pp. 10325-10333, 2001.

[46] Y. Shao and C. H. Dong, "A review on East Asian dust storm climate, modelling and monitoring," Global and Planetary Change, vol. 52, no. 1-4, pp. 1-22, 2006.

[47] W. Qian, L. Quan, and S. Shi, "Variations of the dust storm in China and its climatic control," Journal of Climate, vol. 15, no. 10, pp. 1216-1229, 2002.

[48] X. Liu, Z.-Y. Yin, X. Zhang, and X. Yang, "Analyses of the spring dust storm frequency of northern China in relation to antecedent and concurrent wind, precipitation, vegetation, and soil moisture conditions," Journal of Geophysical Research D: Atmospheres, vol. 109, no. 16, 2004. 
[49] J. Huang, P. Minnis, Y. Yi et al., "Summer dust aerosols detected from CALIPSO over the Tibetan Plateau," Geophysical Research Letters, vol. 34, no. 18, Article ID L18805, 2007.

[50] Z. Yao, J. Li, H.-J. Han, A. Huang, B. J. Sohn, and P. Zhang, "Asian dust height and infrared optical depth retrievals over land from hyperspectral longwave infrared radiances," Journal of Geophysical Research Atmospheres, vol. 117, no. 19, Article ID D19202, 2012.

[51] S. G. Desouza-Machado, L. L. Strow, B. Imbiriba et al., "Infrared retrievals of dust using AIRS: comparisons of optical depths and heights derived for a North African dust storm to other collocated EOS A-Train and surface observations," Journal of Geophysical Research Atmospheres, vol. 115, no. 15, Article ID D15201, 2010. 

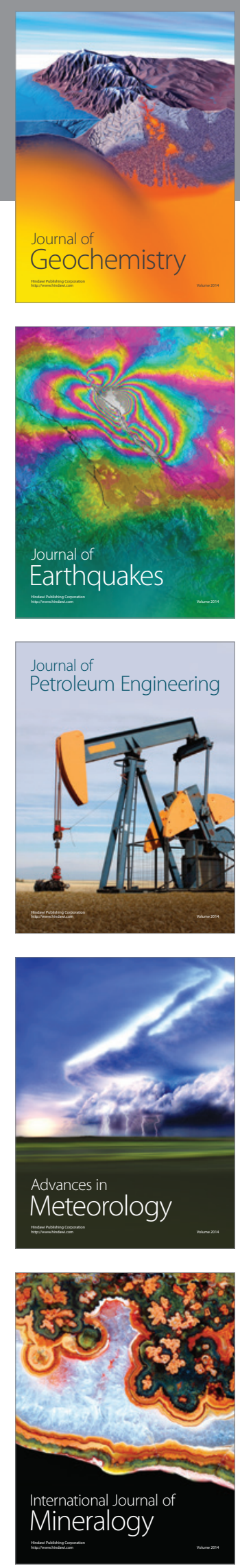
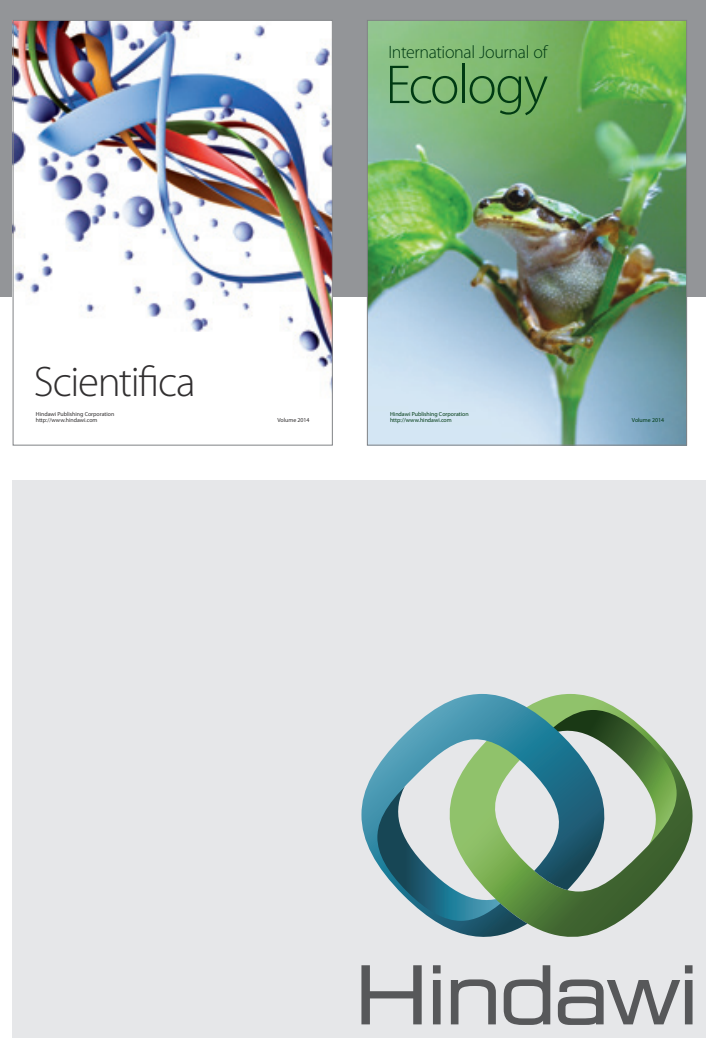

Submit your manuscripts at

http://www.hindawi.com
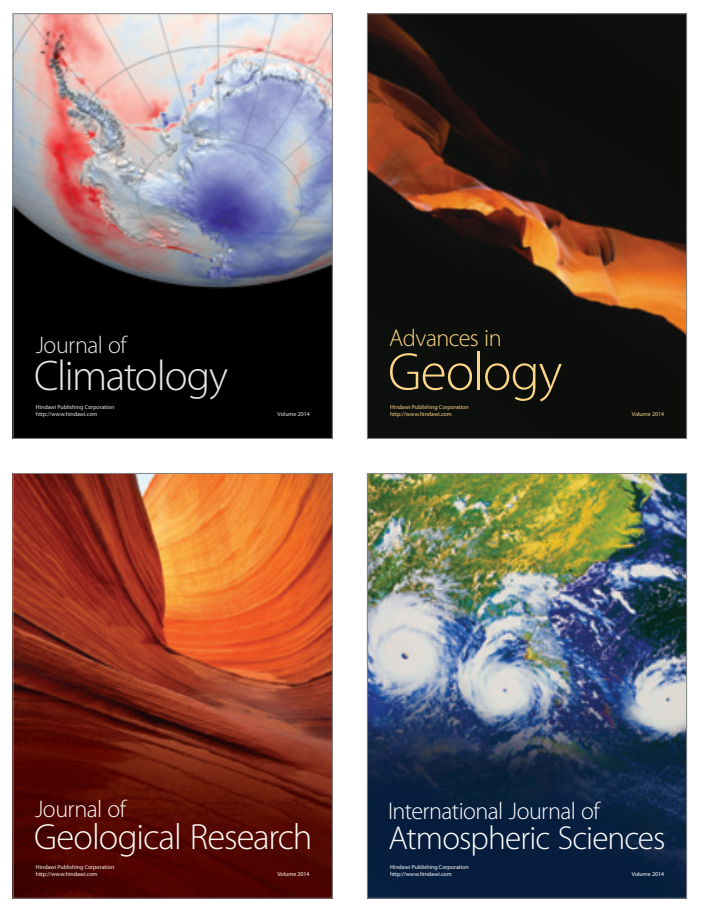

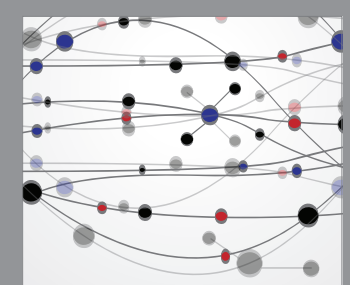

The Scientific

\section{World Journal}
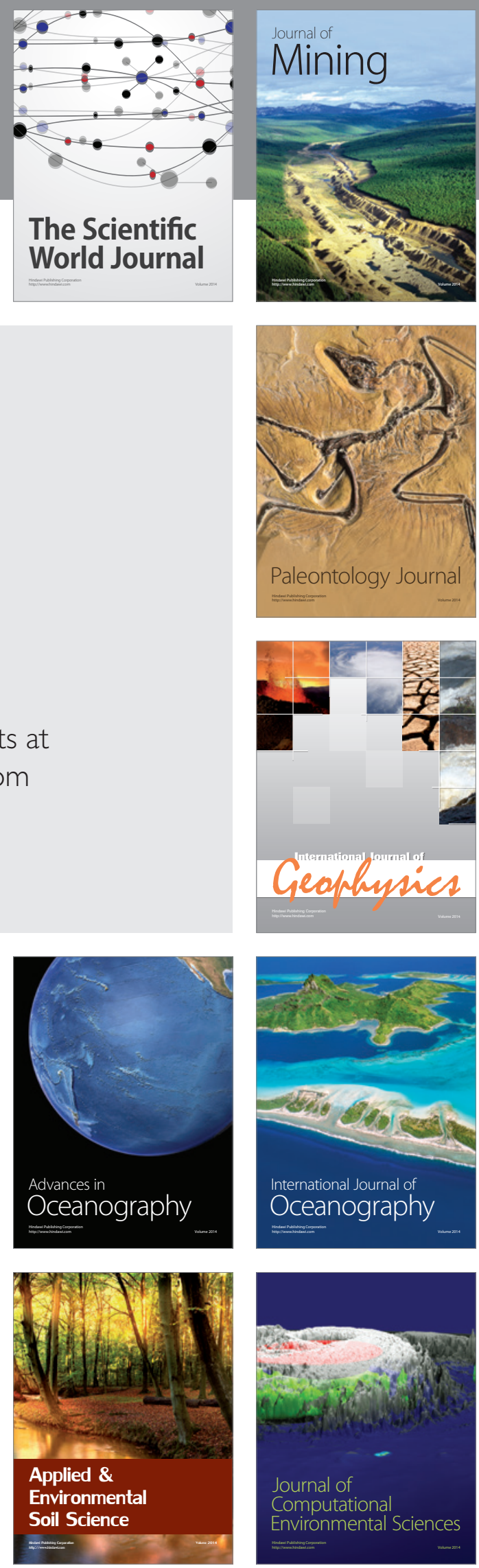